\title{
Los principios de legalidad y seguridad jurídica en la aplicación de la evaluación de desempeño docente
}

\author{
The Principles of Legality and Legal Security in the Application of the Educational \\ Performance Evaluation
}

\begin{abstract}
Os princípios de legalidade e segurança jurídica na aplicação da avaliação de desempenho do professor
\end{abstract}

Marisol Muñoz Juárez

Instituto Superior en Ciencias de la Educación del Estado de México, México

mmj260781@yahoo.com.mx

https://orcid.org/0000-0002-4561-0297

\section{Resumen}

La puesta en marcha de la evaluación de desempeño docente generó en los profesores la manifestación de una serie de inconformidades en cuanto a las formas en cómo la norma establecida se encontraba siendo aplicada, y la constante percepción de que se violentaban sus derechos. Producto de tal observación es que se decidió iniciar la tesis doctoral titulada $L a$ aplicación de la evaluación de desempeño docente. Legalidad y seguridad jurídica: referencias y realidades, cuyo objetivo general fue el análisis acerca de la posible relación existente entre la aplicación de la evaluación de desempeño y los principios de legalidad y seguridad jurídica. De dicha investigación surge a su vez el presente artículo, cuya finalidad no es otra que la de dar a conocer tanto el proceso de construcción como los resultados obtenidos de la tesis doctoral.

Tras un trabajo de recopilación de testimonios focalizados en una muestra de 10 profesores que presentaron la evaluación de desempeño, a los cuales se les aplicó un cuestionario como herramienta de investigación, se pudo inferir una relación existente entre la improvisada aplicación de dicha evaluación con los principios de legalidad y seguridad jurídica. Por lo que, como resultado de una discusión en la que se estableció y reforzó la vinculación entre ambos factores, se plantea la siguiente propuesta: La capacitación de los profesores, cuya obligación 


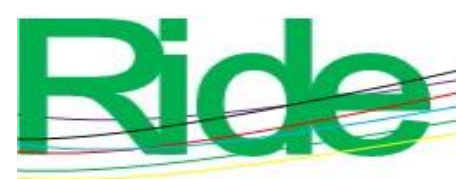

Revista Iberoamericana para la

Investigación y el Desarrollo Educativo

ISSN 2007 - 7467

legal recae en manos del Estado en su carácter de patrón, a través de una política pública diseñada con bases teóricas sólidas de conformación. Además de la reducción de la brecha entre legalidad, seguridad jurídica y aplicación de la evaluación. Esto mediante una reglamentación específica acerca de los procedimientos de aplicación de la misma y la consecuente elaboración de un manual de procedimientos de la evaluación de desempeño docente para regular la aplicación evaluativa de los educadores en cada una de sus fases.

Palabras clave: desempeño, evaluación, legalidad, seguridad jurídica.

\section{Abstract}

The implementation of the teacher performance assessment generated in teachers the manifestation of a series of disagreements regarding the ways in which the established standard was being applied, and the constant perception that their rights were violated. Product of such observation is that it was decided to start the doctoral thesis entitled The Application of the Teacher Performance Evaluation. Legality and Legal Security: References and Realities, whose general objective was the analysis of the possible relationship between the application of performance evaluation with the principles of legality and legal security. As a result of this research, the present article has the objective of informing both the construction process and the results obtained from the doctoral thesis.

After a compilation of testimonies focused on a sample of 10 professors who presented this evaluation, to whom a questionnaire was applied as a research tool, it was possible to infer an existing relationship between the improvised application of said evaluation and the principles of legality and legal security. Therefore, as a result of a discussion that established and strengthened the relationship between both factors, the following proposal is put forward: The training of teachers, whose obligation legal rests in the hands of the State in its character of patron, through a public policy designed with solid theoretical bases of conformation. In addition to reducing the gap between legality, legal security and application of performance evaluation. This by means of a specific regulation about the procedures of application of the same that entails the elaboration of a manual of procedures of the evaluation of teaching performance, whose similarity concerns 


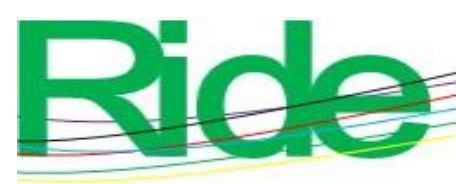

Revista Iberoamericana para la

Investigación y el Desarrollo Educativo

ISSN 2007 - 7467

the innovation of retaking some applicable procedural codes in other matters, to regulate the evaluation of performance in the application of each of its phases.

Keywords: performance, evaluation, legality, legal security.

\section{Resumo}

A implementação da avaliação do desempenho docente gerou nos professores a manifestação de uma série de desentendimentos quanto às formas de aplicação da norma estabelecida e a percepção constante de que seus direitos foram violados. O produto de tal observação é que se decidiu começar a tese de doutorado intitulada A aplicação da avaliação de desempenho de professor. Legalidade e segurança jurídica: referências e realidades, cujo objetivo geral era a análise da possível relação entre a aplicação da avaliação de desempenho e os princípios de legalidade e segurança jurídica. Dessa investigação surge, por sua vez, o presente artigo, cuja finalidade não é senão dar a conhecer tanto o processo de construção quanto os resultados obtidos na tese de doutorado.

Após uma compilação de depoimentos focados em uma amostra de 10 professores que apresentaram a avaliação de desempenho, à qual foi aplicado um questionário como ferramenta de pesquisa, foi possível inferir uma relação existente entre a aplicação improvisada da referida avaliação e os princípios de legalidade e segurança jurídica. Portanto, como resultado de uma discussão em que a ligação entre os dois fatores foi estabelecida e reforçada, a seguinte proposta é apresentada: A formação de professores, cuja obrigação legal recai sobre as mãos do Estado em seu papel de empregador, através de de uma política pública projetada com sólidas bases teóricas de conformação. Além de reduzir a lacuna entre legalidade, segurança jurídica e aplicação da avaliação. Isto mediante uma regulação específica sobre os procedimentos de aplicação do mesmo e a conseqüiente elaboração de um manual de procedimentos da avaliação de desempenho educacional para regular a aplicação avaliativa dos educadores em cada uma de suas fases.

Palavras-chave: desempenho, avaliação, legalidade, segurança jurídica.

Fecha Recepción: Marzo 2018

Fecha Aceptación: Septiembre 2019 


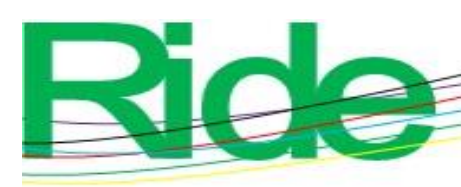

Revista Iberoamericana para la

Investigación y el Desarrollo Educativo

ISSN $2007-7467$

\section{Introducción}

Atendiendo a los antecedentes que conllevan a la realización del presente artículo, se sitúa en el contexto del año 2018. A estas alturas se está llevando a cabo el proceso de evaluación de desempeño para el cuarto grupo de profesores, conforme a la reforma constitucional del año 2013, la cual plantea por primera vez una evaluación de desempeño y cuyo primer grupo inicia en el 2015. Lo anterior en un marco de confusión que conlleva a llamarla —en el peor de los casos-y por algunas normas "evaluación de permanencia".

Incertidumbre, sensación de vulnerabilidad y sentimientos de indefensión se instauraron en la piel del docente que se enfrentaba por primera vez a un proceso de evaluación en el que, se decía, estaba en juego su estabilidad laboral. ¿Estaban los profesores equivocados al asumir un rol de sujetos pasivos frente a este tipo de políticas gubernamentales?

De igual manera, en el desarrollo del presente artículo constantemente se presentó una intensa incertidumbre de no estar a la altura de los requerimientos básicos de dogmatismo teórico que se le exigen al investigador. Colocar un punto de vista jurídico en el marco de las ciencias de la educación conlleva un enorme desafío ante una comunidad que se especializa en temas preferentemente pedagógicos. De forma análoga a lo que alude Villa (2013), me planteé las interrogantes: ¿Por qué no abordar el problema jurídico que enfrentan los docentes en su evaluación de desempeño?, ¿acaso la norma que establece los parámetros bajo los que se rige el docente no incide en su vida laboral?, ¿la mirada jurídica trasciende a los asuntos educativos?

\section{Cuestiones de implicación}

El tejido del objeto de estudio no fue asunto sencillo. Desde la empiria se echó una mirada la forma en cómo la aplicación de la evaluación de desempeño docente vulneraba de alguna manera los principios de legalidad y seguridad jurídica. Es algo que no se visualizó desde lejos, sino como sujeto mismo de evaluación. Dicha observación no fue neutra, estuvo cargada de una fuerte postura y teoría jurídica que interpelaba a mi formación como licenciada en Derecho y maestra en Derecho Constitucional (Sánchez, 2000).

Así, se decide escribir este artículo, "Los principios de legalidad y seguridad jurídica en la aplicación de la evaluación de desempeño docente", el cual da cuenta de una exhaustivo trabajo de investigación, producto de la tesis doctoral dentro del Doctorado en Ciencias de la Educación 


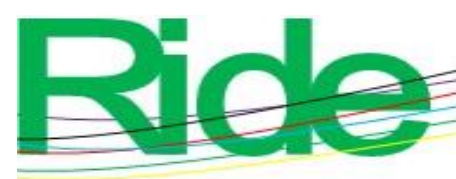

Revista Iberoamericana para la

Investigación y el Desarrollo Educativo

ISSN 2007 - 7467

que imparte el Instituto Superior de Ciencias de la Educación del Estado de México, como una forma de aportar — desde la mirada jurídica que atraviesa la multidisciplinariedad del campo de las ciencias de la educación - una percepción muy particular de la realidad actual e imperante en el terreno del derecho, en particular en la aplicación de la evaluación de desempeño docente que, además de incidir de manera directa en los principios jurídicos de que son garantes los profesores, impacta en los diversos fenómenos educativos que tienen lugar dentro de las instituciones escolares.

Coincido con Sánchez (2000) en que esta investigación tiene que ir más allá de la exposición de la verdad; es necesaria una intervención que transforme las condiciones con las cuales se está aplicando la evaluación docente apegada al respeto por la norma jurídica. La identificación plena de esta problemática, si bien comienza desde la empiria debida a la experiencia personal y de compañeros docentes, como ya se mencionó, se sustenta en el conocimiento previo: una fuerte carga de teoría jurídica subyacente a mi formación profesional.

Por lo tanto, el principal objetivo de la tesis doctoral antes citada, antecedente y causa del presente artículo, es analizar y explicar la relación entre la aplicación de la evaluación de desempeño docente con los principios jurídicos de legalidad y seguridad. Motivo por el cual se supone que existe dicha relación.

Reconociendo una mirada multidisciplinaria desde el ámbito jurídico, se invita a ver el fenómeno de la aplicación de la evaluación de desempeño como un acto que interviene en la actuación del docente como sujeto de derecho a la legalidad y seguridad jurídica. Y cuya construcción epistémica lleva a revisar los postulados de los principios jurídicos de la teoría de Heller (1992), quien establece que "nunca está contenido todo el derecho en la letra de los preceptos jurídicos positivos" (p. 76), y que todo derecho positivo o escrito debe descansar sobre la base de ciertos preceptos éticos y morales concretos que funcionan como directrices generales sobre los cuales deciden los miembros de una comunidad jurídica. Los cuales no cumplen una función específica para un caso en particular, sino una interpretación general de la constitución (Vita, 2015).

Anclados en la anterior definición, los principios jurídicos son normas de carácter moral que se posicionan por encima de la norma escrita con la finalidad de ajustar el actuar de la autoridad a bases éticas que respeten los preceptos constitucionales y de derechos humanos de los 


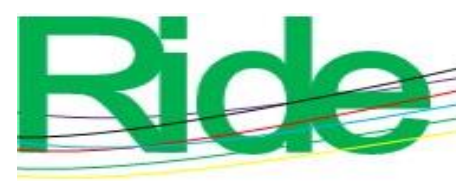

Revista Iberoamericana para la

Investigación y el Desarrollo Educativo

ISSN 2007 - 7467

que son garantes los ciudadanos. Así, pues, tanto la legalidad como la seguridad jurídica son principios de derecho que deben estar insertos no solamente en el texto de la norma, sino en el actuar cotidiano de la autoridad cuando emite actos que infieren en la esfera jurídica del gobernado.

\section{El método}

El método utilizado para el desarrollo de la tesis doctoral ya especificada versó, en primer lugar, en una identificación del problema en la realidad que se vive en el proceso de aplicación de la evaluación de desempeño docente, lo cual se sustentó con los testimonios focalizados de

profesores evaluados, quienes aludieron violaciones constantes a los principios de legalidad y seguridad jurídica al momento de presentar cada una de las etapas del proceso evaluativo. Ahí comienza la inquietud por la problemática.

Cabe mencionar que los docentes, al comentar sus vivencias, evidentemente no las etiquetaron como incidencias a principios jurídicos - es ahí donde la empiria se rebasa y robustece por los presupuestos teóricos obtenidos a lo largo de mi formación académica y profesional, es decir, por mi mirada de jurista.

Acto seguido, se indaga acerca de los principales fenómenos asociados a la problemática, tales como la preparación de los evaluadores, el concepto de buen maestro, los medios de logística aplicados al proceso de evaluación, el acceso de los docentes a cursos de formación continua, entre otros.

Derivado de lo anterior surge la pregunta de investigación: ¿Cómo se establece la relación entre la aplicación de la evaluación del desempeño docente y los principios de legalidad y seguridad jurídica?

Una vez delimitada la pregunta de investigación, fue preciso indagar acerca de quiénes han tratado de darle respuesta y de qué manera lo han hecho, a fin de reconocer la aportación que como investigador se pretende dar al campo de conocimiento, así como la toma de postura que se tendrá en cuanto al tema.

De dicha indagatoria se advirtieron diversas investigaciones que el propio Instituto Nacional para la Evaluación de la Educación [INEE] (2017) ha realizado en cuanto a los procesos 


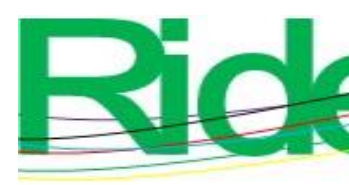

Revista Iberoamericana para la

Investigación y el Desarrollo Educativo

ISSN 2007 - 7467

de evaluación de desempeño acaecidos en los años 2015 y 2016 con el ánimo de realizar un balance de los logros y desafíos detectados como áreas de oportunidad.

A su vez, el propio INEE emite en el año 2016 una publicación que retoma las percepciones y situaciones de incertidumbre y estrés que han enfrentado algunos docentes dentro de cada una de las fases del proceso, para dar paso a una serie de propuestas de mejora, recogiendo la opinión de los docentes mediante una consulta a lo largo de las distintas entidades federativas de México y reconociendo los contextos de cada una de ellas. Y en la cual destacan las incidencias reportadas por los maestros a la hora en que se enfrentan a su evaluación de desempeño (INEE, 2016).

Del análisis empírico y teórico previamente establecido se establece como supuesto de investigación que la manera en que se ejecuta la aplicación de la evaluación del desempeño incide de alguna forma en los principios de legalidad y seguridad jurídica de los docentes que presentan la evaluación. Así, pues, se fija como objetivo central de la investigación: Analizar y explicar la relación entre la aplicación de la evaluación del desempeño docente y principios de legalidad y seguridad jurídica.

Para cumplir con el objetivo general antes enunciado se comienza por indagar los orígenes de la evaluación, y se encontró que, epistemológicamente, desde el paradigma positivista, la evaluación se ha definido como una actividad sistemática para determinar el valor de algo. Esto a partir de una serie de pasos que consisten en una recogida de información, interpretación de la información bajo patrones de deseabilidad y la emisión de un juicio de valor, ya sea para orientar la acción o tomar decisiones (Popham, 1980).

Es decir, tomando en cuenta que la evaluación educativa y más aún la de desempeño docente son auspiciadas por un pensamiento positivo encaminado a determinar el qué, cómo, cuándo y por qué de la enseñanza de tales o cuales conocimientos, es en dicha tradición epistemológica que se sustenta no solamente la conceptualización de la evaluación, sino de la calidad educativa que se pretende alcanzar con la misma y de la norma jurídica -igualmente positiva - que da lugar a su implementación como política de gobierno.

De tal suerte que los conocimientos que poseen los docentes son evaluados en razón de su funcionalidad para el sistema hegemónico, lo cual trae consigo que entre pares se reconozcan y distingan del resto. Se trata de constituir una nueva clase de intelectuales docentes: entre más 


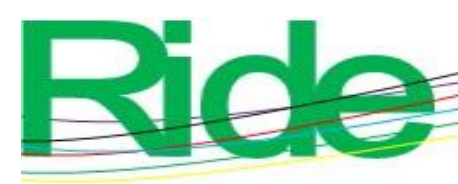

Revista Iberoamericana para la Investigación y el Desarrollo Educativo ISSN 2007 - 7467

profesionalizados se encuentren más podrán instituirse como reproductores del discurso teórico de la calidad educativa (Gouldner, 1980).

El anterior es el concepto de evaluación que retoma la autoridad educativa. Es por eso por lo que no es de extrañarse que los docentes lo asuman como una forma reguladora de las prácticas que han dominado a lo largo de toda su trayectoria profesional. Y es que mediante el uso del lenguaje se propone una lógica de encasillamiento en determinados niveles de desempeño, cuando son situados como destacados, buenos o suficientes (Bourdieu, 2009).

Respecto al marco teórico, el concepto de evaluación es delineado por autores como Shepard (2006), quien analiza esta práctica a partir de procedimientos estandarizados para fijar valor; Coll (1996), quien establece una correspondencia entre los procesos de aprendizaje de los alumnos con las estrategias de enseñanza planteadas por el docente; Frida Díaz (2001), autora que integra el elemento reflexivo a partir de los resultados de la evaluación y la importancia de la contextualización de la práctica docente, y Sacristán (1998), quien inserta el factor del evaluador como sujeto poseedor de prenociones acerca de aquel a quien evalúa.

En un análisis del marco antes planteado, se construye una definición de la evaluación como un proceso formativo y continuo tanto del alumno como del docente en cuanto a las estrategias de enseñanza-aprendizaje implementadas, cuyo eje fundamental se centra en los contextos y dinamismos de la vida cotidiana que rescatan las subjetividades del evaluador y evaluado, y cuyos resultados podrán servir de base para reflexionar y tomar decisiones en cuanto a las áreas de oportunidad en que se habrá de trabajar.

Así, la evaluación del desempeño docente, tal como es definida y considerada por las autoridades educativas de nuestro país para su posterior legislación, estructuración, objetivos, finalidades, alcances y consecuencias, se adapta al paradigma positivista, verificador de conductas y conocimientos que el profesor debe poseer frente al aula, y cuyas cualidades serán validadas por perfiles, parámetros e indicadores previamente establecidos.

Por otro lado, el bosquejo histórico del concepto de evaluación me llevó a indagar sobre las cuatro coyunturas específicas enunciadas por Gimeno Sacristán (1998) en concordancia con Guba y Lincoln (1989). 


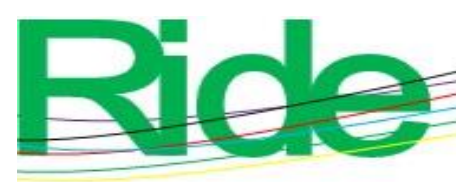

Revista Iberoamericana para la

Investigación y el Desarrollo Educativo

ISSN 2007 - 7467

Ambas fuentes enuncian estas coyunturas como tradiciones que van desde un autoritarismo donde la evaluación era aplicada por un experto mediante instrumentos que este mismo diseñaba y cuya discrecionalidad quedaba al arbitrio de los conocimientos que consideraba el evaluador debía poseer o no el evaluado; para dar paso a una segunda ampliamente influenciada por el positivismo: un proceso que verifica paso a paso si los contenidos del currículo se han alcanzado, basada en parámetros estandarizados aplicables a grandes grupos. Más adelante, en una tercera tradición identificada, se considera la evaluación en un sentido conductista y propiciador de un cambio conductual o reflexivo en el evaluado. Finalmente, se da paso a una cuarta coyuntura, en donde se exige que se rebase al positivismo y que se tomen en cuenta los diversos contextos de manera holística.

Sin embargo, el análisis de cada una de las etapas del proceso de evaluación de desempeño docente actualmente aplicado en nuestro país conlleva circunscribir la discusión sin nunca perder de vista la temporalidad del objeto atravesado por el neoliberalismo, la globalización, las formas hegemónicas internacionales de ejercicio del poder que no rebasan el posicionamiento positivista. De ahí que se retomó una articulación que se encamina al positivismo para el análisis del tema en cuestión para, desde dicho paradigma, proponer maneras de intervenir en la realidad que tiendan a dotar de los principios jurídicos fundamentales de legalidad y seguridad a los profesores evaluados.

La evaluación docente como un concepto que engloba una totalidad atravesada por la producción, el régimen económico neoliberal, el ejercicio de poder, la norma jurídica, la legalidad, no se desvincula de su contenido histórico, social, jurídico (Perujo, 2011).

De esta manera se inserta el objeto de estudio correspondiente a la evaluación de desempeño docente en el campo de las ciencias sociales a partir de la teoría positiva del derecho, cuyo fundamento científico ha permitido regular las relaciones de convivencia dentro de la sociedad desde sus orígenes hasta la legislación vigente.

Fundamentar la investigación en la teoría del derecho y en la teoría de la evaluación hace sobrepasar las prenociones de sentido común que se pudieran tener en torno a la evaluación de desempeño docente aplicada en México, además de un cuidado riguroso del lenguaje empleado en la exposición del texto cuyo intento por situar su análisis en una postura neutral se apoya en el corte contextual histórico que se hace del concepto de evaluación (Gouldner, 1980). 


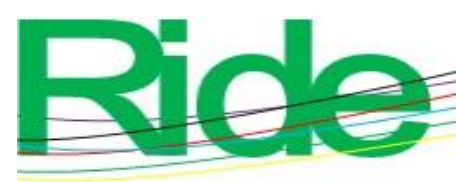

Revista Iberoamericana para la

Investigación y el Desarrollo Educativo

ISSN 2007 - 7467

Así, la postura positivista e instrumental desde la cual se implementa en el año de 2013 la evaluación de desempeño docente en la norma suprema de nuestro país no es fortuita sino que está inmersa dentro de todo un sistema jurídico cuya base se sustenta justamente en la teoría del derecho positivo.

Por eso, en el presente artículo se rescata una visión de la realidad sustentada en la teoría positivista del derecho, referida en una captación del sentido del deber ser, en cuyo discurso de legalidad se sustenta el análisis de la aplicación de la evaluación del desempeño. Dicho deber ser, de acuerdo con Gouldner (1980), despliega una forma de control sobre la sociedad que, en nuestro trabajo, se vislumbra como una forma de ejercicio de poder a partir de la modificación constitucional mediante la cual se crea esta práctica de examinación docente, y en cuyo eje de análisis se dirime en cuanto la forma de aplicación que infiere en los principios jurídicos de legalidad y seguridad. Sin embargo, desde ese mismo ejercicio de derecho se proponen vías de intervención en la realidad que ayuden a subsanar la aplicación de tales principios jurídicos fundamentales.

Sin duda, cuando se enuncian las categorías de "principio jurídico de legalidad", "seguridad jurídica", "evaluación de desempeño", se hace desde una noción que retoma el deber ser de acuerdo a principios ideológicos que me posicionan como sujeto de un lenguaje jurídico que defiende el respeto al marco normativo del derecho positivo, aunado al profundo apego a los principios jurídicos. Desde ese punto de vista es que analizo la forma en cómo los procedimientos de aplicación de la evaluación docente no se constriñen a los principios de legalidad y seguridad jurídica, cuyo sustento y contraste se basa en los testimonios focalizados de los docentes evaluados (De la Garza, 1988).

En su articulación, se retoma la teoría positiva del derecho, en su vínculo directo con la construcción epistemológica e histórica de la categoría "evaluación del desempeño docente", acerca de cómo se ha concebido la "evaluación" desde sus inicios hasta llegar a la noción actual de la misma y sobre la cual se cimentan las acciones para su ejecución. Aunado a ello, se retoma una postura jurídica con los testimonios focalizados de los profesores evaluados, quienes dan cuenta de la contradicción existente entre la norma escrita, la norma aplicada y una norma inexistente. 


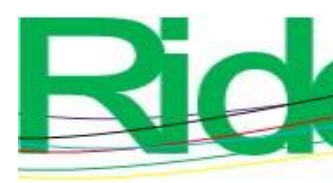

Revista Iberoamericana para la

Investigación y el Desarrollo Educativo

ISSN 2007 - 7467

En esta investigación, el testimonio focalizado se emplea como técnica de investigación; técnica que aquí se considera la más apegada al método jurídico de investigación propuesto en el desarrollo de este trabajo. Por principio de cuentas, es de vital importancia indagar acerca de la epistemología que enviste al testimonio, a fin de explicar sus orígenes y su pertinente aplicación en este trabajo.

En efecto, producto de dicho análisis epistemológico de nuestra técnica de investigación se encontró que Andrés Páez (2014), en su artículo "La prueba testimonial y la epistemología del testimonio", arguye la epistemología del testimonio a partir del reduccionismo y el antirreduccionismo como posturas opuestas. Para el análisis del reduccionismo, Páez (2014) recurre a la explicación de David Hume (1980), de quien expone la confianza que generalmente se atribuye a los testimonios de los demás como fuente de la verdad y a lo que denomina reduccionismo global; frente al testimonio particular en contextos determinados identificados como un reduccionismo local. Así, se torna reduccionismo en tanto el testimonio se reduce a fuentes epistémicas que se justifican a través de los sentidos del testigo, su memoria y su razonamiento inductivo. Postura reforzada por las aportaciones de Thomas Reid (1764), quien sostiene que "en la socialización del hombre existen dos posturas: un principio de propensión a decir la verdad a través de todas las formas del lenguaje y, la disposición a confiar en lo que dicen los demás" (p. 194).

Respecto al antirreduccionismo, Páez (2014), citando a Hardwing, dice que nuestras más profundas creencias provienen de fuentes testimoniales en las cuales asentamos tal grado de confiabilidad que no dudamos de ellas. Ejemplifica diciendo que el ser humano se desarrolla en parte a través de un proceso de socialización en el cual las figuras que están al cuidado de su formación le van contando su propia historia y miradas del mundo, las cuales no son puestas en duda en virtud de provenir de fuentes confiables, y cuyas creencias no son sometidas tampoco a experimentación.

Menciona como ejemplo que cuando a un niño sus padres le cuentan la historia de su nacimiento, lugares, acerca de quiénes son sus parientes cercanos o la identidad de sus padres, dichas verdades no son sujetas a cuestionamientos porque la fuente de información es de tal confianza que será difícil que en la vida adulta se sometan a verificación los testimonios escuchados (Páez, 2014). 


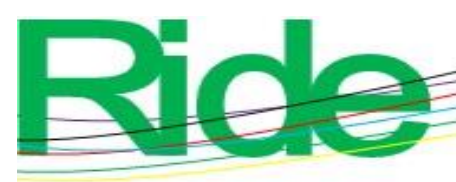

Revista Iberoamericana para la

Investigación y el Desarrollo Educativo

ISSN 2007 - 7467

En lo que respecta a este trabajo, los testimonios focalizados recabados de los docentes a quienes se les aplicó la evaluación de desempeño se obtuvieron a través de un cuestionario como herramienta, a partir de un universo de 29043 docentes que a nivel nacional han sido evaluados en su desempeño para el caso de la educación media superior, de acuerdo con datos extraídos de informes del INEE. Más específicamente, la población objetivo se centró en los 3568 docentes de nivel medio superior del Estado de México, cuya muestra sujeta de análisis para la investigación fue de 10 testimonios focalizados.

Una vez dada la explicación anterior es importante mencionar que la metodología empleada en la articulación de esta investigación fue de carácter inductivo, en la cual, a través de la explicación de la teoría acerca de la conceptualización de la evaluación del desempeño docente, principalmente cimentada en la investigación documental, se retoma como técnica el testimonio focalizado a profesores evaluados.

Citando a Grawitz (1975): "La tarea no es contemplar lo que nadie ha contemplado, sino meditar lo que nadie ha meditado aún sobre lo que todo mundo tiene frente a los ojos" (p. 14). Con relación a ello, la metodología que demandaba la construcción del análisis de la aplicación de la evaluación de desempeño con relación a los principios de legalidad y seguridad jurídica suponía sustentarse en la teoría del derecho para estructurar el desarrollo del trabajo (Grawitz, 1975).

De acuerdo con ello, la teoría del derecho explica una jerarquía de las normas jurídicas que encuentran en su cúspide al derecho internacional y la constitución política de cada nación en el mismo nivel jerárquico, seguido por las legislaciones locales, los reglamentos, hasta llegar a las de aplicación particular. Sin embargo, todas ellas atendiendo a principios fundamentales y filosóficos sobre los cuales se deben sustentar.

Se trata de una metodología de articulación jurídica en la construcción del tema. Si bien se inicia por el análisis epistemológico, teórico e histórico que atraviesa la evaluación del desempeño docente, se llega a la conceptualización actual que hace la autoridad educativa basada en un discurso de corte internacional que se ve influido por factores de tipo económico y cuya pertenencia a dicha comunidad obliga a nuestro país a adecuar sus políticas educativas.

En consecuencia, y acorde con el método mencionado, se ubican los orígenes de la evaluación de desempeño docente en el derecho internacional mediante el análisis de diversos 


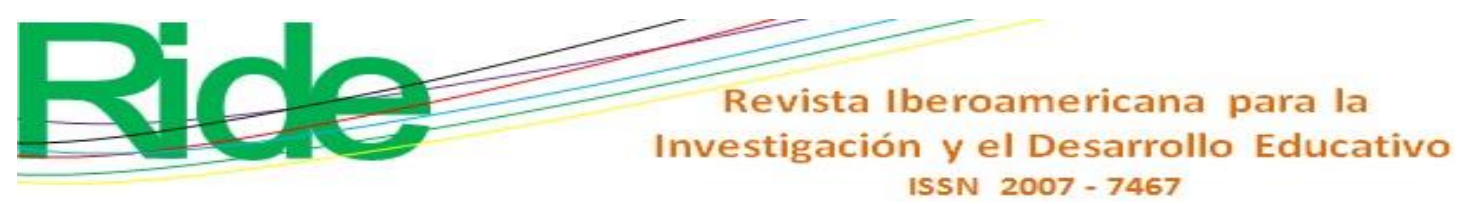

foros educativos que tuvieron lugar previo a su implementación en la reforma constitucional al artículo tercero; reforma que, como es bien sabido, tuvo lugar en el año 2013.

Acto seguido, se realiza una explicación y análisis de la evaluación docente en el ámbito nacional. Así, a partir del estudio de la normatividad jurídica mexicana, que inicia por la Constitución Política de los Estados Unidos Mexicanos, la Ley General de Educación, la Ley General del Servicio Profesional Docente, la Ley del Instituto Nacional para la Evaluación de la Educación, se va ejemplificando con los testimonios de los docentes a quienes se han aplicado los procesos de evaluación de desempeño a fin de establecer la relación existente en la realidad con los principios de legalidad y seguridad jurídica.

Deseo reforzar que el testimonio focalizado de los docentes evaluados fue considerada la técnica que más empataba con la teoría jurídica para dar cuenta de la realidad que se vive en la aplicación de la evaluación de desempeño; testimonios que son retomados a lo largo de la investigación para ejemplificar y explicar la relación entre conceptos.

Sin duda, dos grandes hallazgos surgen en el transcurrir de la investigación. Por un lado, a partir del análisis de la normatividad en su contraste con la realidad testificada por los docentes, se visualiza la falta de políticas públicas encaminadas a la formación continua de los profesores o, en su más incipiente acepción, a la capacitación de maestros para presentar su evaluación; capacitación que se encuentra obligado a proporcionar el Estado en su carácter de patrón. Y, por otro lado, la existente incidencia a los principios jurídicos de legalidad y seguridad jurídica ante la falta de criterios normativos que regulen la aplicación de la evaluación de desempeño docente.

Como se observa, la realidad en la aplicación de la evaluación anima a querer intervenir en ella a partir de la teoría del derecho, no sin antes analizar su contextualización en la teoría, epistemología e historia de la evaluación como concepto central de este trabajo (Limoeiro, 1977). Lo anterior para dar cuenta la relación existente entre la teoría educativa y la evaluación como dispositivo en que se ven inmersas la legalidad y la seguridad jurídica, donde el concepto de evaluación de desempeño engloba fenómenos propios de la economía, la productividad, el neoliberalismo, pero en este caso concreto de lo jurídico. Este es el punto de análisis y de intervención sobre una realidad concreta en constante movimiento que informa a la teoría. 


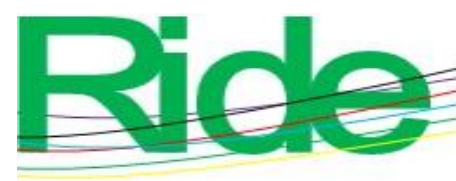

Revista Iberoamericana para la

Investigación y el Desarrollo Educativo

ISSN 2007 - 7467

\section{Cuestión de principios}

El principio jurídico de legalidad podría expresar su vinculación con el hecho de que tanto la actuación del ciudadano como de la autoridad se encuentran dentro de los parámetros establecidos por la ley. Sitlali Torruco (Guba y Lincoln, 1989) considera el principio de legalidad como el más importante dentro del Estado de derecho, porque entraña que lo administrativo debe ceñir su actuar a lo que disponga la ley.

Puesto que la historia de la humanidad se ha visto plagada de casos donde el ejercicio ilimitado y dictatorial del poder ha conllevado a la ejecución de actos de autoridad que han traído innumerables injusticias frente a los particulares. Miguel Carbonell (2004), en su obra Los derechos fundamentales en México, expresa que la Declaración de los Derechos del Hombre y del Ciudadano de 1793, en su artículo octavo, establece: "La seguridad consiste en la protección acordada por la sociedad a cada uno de sus miembros para la conservación de su persona, de sus derechos y de sus propiedades" (s.p.).

Frente al abuso y uso arbitrario del poder se trató de brindar cierta protección, un nivel que dotara de seguridad a los miembros de la sociedad en el sentido de que las actuaciones de la autoridad estarían limitadas por un ordenamiento jurídico que estableciera qué les estaba permitido y qué no. De acuerdo al principio jurídico de legalidad del que ya se ha hablado, los actos de autoridad debieran ser previstos por una ley que fijara con exactitud las funciones y facultades de la autoridad para establecer sanciones, directrices, procedimientos de aplicación de la norma, entre otros.

Juan Antonio Toscano Ortega (2002) menciona lo siguiente:

La seguridad jurídica responde a la aspiración del ser humano de estar regido por un Derecho que le proporcione certidumbre, confianza, estabilidad. De ahí el carácter fundamental e irrenunciable de este principio, que debe salvaguardarse a toda costa frente y pese a las serias amenazas de que está siendo objeto en nuestro ordenamiento jurídico y en la práctica totalidad de Estado de nuestro entorno (p. 96). 


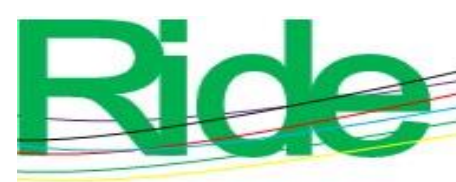

Revista Iberoamericana para la

Investigación y el Desarrollo Educativo

ISSN 2007 - 7467

Así, en la construcción de la investigación, al momento de analizar cada uno de los testimonios focalizados de los docentes evaluados, se llega a la inferencia de la relación existente entre las formas que ha tomado la aplicación de la evaluación de desempeño, en el sentido de su improvisación ante la falta de parámetros normativos que la regulen y que dejan en estado de indefensión al docente como sujeto de derecho. Puesto que no todos los aconteceres, términos administrativos, procedimientos logísticos, causas y excepciones, notificaciones, motivos de suspensión, etc., se encuentran en algún documento legislativo de aplicación general, lo cual despoja de seguridad jurídica al profesor como gobernado, debido a que no conoce de antemano el precepto legal que ha de regular su actuar y sus posibles consecuencias.

Por ello la aplicación de la evaluación del desempeño docente se coloca en un escenario, visto desde un enfoque jurídico, que conlleva la imperiosa necesidad de vincularla con la teoría jurídica kelseniana en cuanto a la jerarquización del derecho, y se sitúa dentro del derecho educativo, y su jerarquía dentro del derecho internacional y nacional, hasta llegar al acto particular de su aplicación.

Para lograrlo, se rastrea la trayectoria jurídica de la evaluación del desempeño docente en el ámbito internacional, a partir del análisis de diversos foros mundiales sobre educación, en el marco de un discurso educativo globalizador que es sustentado en el análisis de documentos emergentes de los mismos, tales como:

1) El Informe Faure, que señala la importancia de que la educación impartida por el Estado atienda a las necesidades del mundo global; y que las competencias que posea el docente dentro de ese proceso sean verificadas mediante la evaluación de su práctica (Faure, 1973).

El análisis de tal documento se va contrastando en su construcción con las posiciones teóricas de diversos autores en torno a la reflexión acerca de la implementación de directrices internacionales en la política pública nacional. Retomando a Almandoz (2005), quien formula que para implementar las directrices internacionales en nuestro país la política educativa debe reconocer la educación como el espacio público en el cual surge y se posibilita la acción política, por lo que, en consecuencia, se desmarca de los intereses de mercado que la impregnan. Además del análisis de Felipe Aguilar (2000), que diferencia la política pública educativa de una política de gobierno en términos de que esta es diseñada de forma vertical desde el Gobierno y baja a ser 


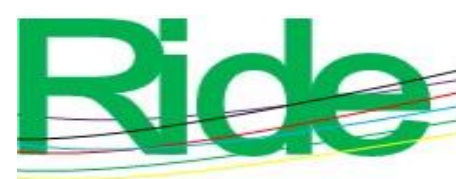

Revista Iberoamericana para la

Investigación y el Desarrollo Educativo

ISSN 2007 - 7467

aplicada a las bases de la sociedad; mientras que las políticas públicas son creadas en diálogo con los diversos sectores de la sociedad a las que van destinadas.

2) Declaración mundial sobre educación para todos. Marco de acción para satisfacer las necesidades básicas de aprendizaje (1990), documento fruto del foro homónimo en el que se proclama a la década de 1990 como la indicada para llevar a cabo los ajustes necesarios tendientes a elevar la calidad de la educación, como una meta nacional apoyada por el ámbito internacional, ya sea en cooperación académica o financiera. Y en cuya primera etapa los países participantes se comprometen a realizar una evaluación integral de las condiciones educativas, lo cual incluye a los docentes.

3) Jacques Delors: La educación encierra un tesoro. Informe a la Unesco de la Comisión Internacional sobre la Educación para el Siglo XXI (1996), donde se plantea que el problema fundamental de establecer una reforma que lleve a cabo la educación para toda la vida es qué política educativa resulta pertinente para fomentar en niños y adolescentes la educación a lo largo de toda la vida. Para ello, se torna necesaria una mejor gestión de los recursos humanos que dispone el sistema educativo, a saber: los docentes.

4) Foro Mundial sobre la Educación, Dakar. Se trata de un espacio donde se propone como uno de los puntos medulares en la calidad de la educación la aportación de docentes bien capacitados y competentes, que cuenten con mayor apoyo institucional que les permita la formación continua, plenamente motivado por un sistema de incentivos (Organización de las Naciones Unidas para la Educación, la Ciencia y la Cultura [Unesco], 2000).

El anterior contexto internacional da cuenta del origen jurídico que enviste la conceptualización de la evaluación de desempeño docente, la cual será posteriormente aplicada al marco jurídico vigente nacional como una forma de dar cumplimiento a las directrices internacionales pactadas en tales foros. De tal forma que, para dar continuidad a la ubicación de la evaluación de desempeño docente dentro del derecho positivo mexicano, una vez examinada la ubicación internacional de la misma, es turno de hablar de su lugar dentro de la jerarquía del derecho mexicano, de acuerdo con el artículo 133 constitucional. Esto abarca desde un análisis de la Ley General de Educación, la Ley General del Servicio Profesional Docente, la Ley del Instituto Nacional para la Evaluación de la Educación, hasta su aplicación individual en cada uno de los procesos a los que se atienen los profesores que presentan la evaluación de desempeño. 


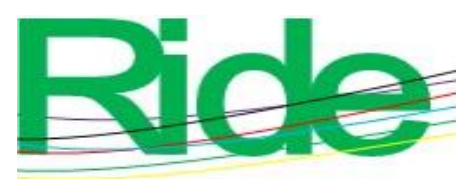

Revista Iberoamericana para la

Investigación y el Desarrollo Educativo

ISSN 2007 - 7467

La incidencia de los procesos de aplicación de la evaluación de desempeño docente con respecto a los principios de legalidad y seguridad jurídica cobran su principal objetivación en los testimonios focalizados de docentes que han sido evaluados, los cuales sirven de referentes y fuentes de datos decisivos para determinar el nivel de realidad jurídica que desarticula el discurso normativo de la evaluación. Puesto que, en términos de Popper (Rosario, 2010), bastaría con un solo testimonio para dar cuenta que la teoría legal, en cuanto a los principios de legalidad y seguridad jurídica, en la aplicación de la evaluación de desempeño docente se están violentando.

Dar cuenta de un determinado momento de la realidad tal y como la ha concebido el sujeto a partir del testimonio conlleva una arqueología epistemológica desde el supuesto teológico hasta filosófico, que postulaba Kant como el imperativo categórico cuyo deber supremo moral del hombre era conducirse con verdad. Este es retomado por la teoría del derecho, donde cobra vital importancia el testimonio como una técnica de recogida de información en la cual se da por sentado que aquel que enuncia se encuentra diciendo la verdad en el terreno del deber ser.

\section{Discusión y resultados}

Este artículo, a la vez que da cuenta del proceso metodológico de construcción de la tesis doctoral ya enunciada, a saber, La aplicación de la evaluación de desempeño. Legalidad y seguridad jurídica: referencias y realidades, sirve como una invitación directa a la lectura pormenorizada de tal documento, puesto que, tal como lo postulan Edelstein y Rodríguez (1974), en las conclusiones de la tesis se ofrecen alternativas de solución cuyas posibilidades de aplicación no caen en salidas utópicas o inaplicables en la realidad concreta. Por el contrario, se ofrece una salida sustentada en la teoría del derecho que se ha trabajado en el transcurrir de la investigación.

La discusión principal que se dirime gira en torna a la forma en cómo los principios de legalidad y seguridad jurídica se ven afectados en el momento preciso en que se aplica la evaluación de desempeño docente, tal y como se confirma con cada uno de los testimonios focalizados de los docentes a los cuales se les aplicó la técnica de investigación.

Así, de los 10 docentes a los que se les aplicó el cuestionario, cada uno de ellos comentó situaciones que no se encuentran normadas por la legislación en materia de evaluación de desempeño, sino basadas en decisiones administrativas que se colocan por encima del poder 


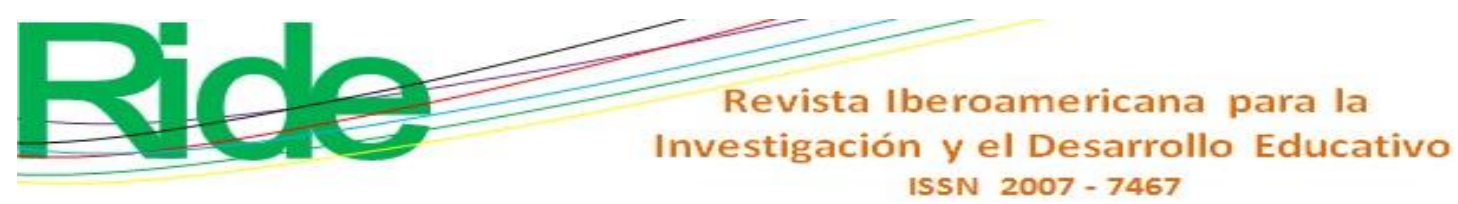

legislativo al existir lagunas jurídicas. De lo cual se concluye que es necesario normar específicamente cada una de las cuestiones, tiempos, sanciones, sujetos, consecuencias de su actuar, que queden estipuladas dentro de la ley.

Además, como punto de partida, la obligación patronal del Estado de capacitar al docente en su carácter de trabajador, a partir de un análisis de la instauración como política pública en la que todos los participantes converjan en un diálogo que lleve a la toma de decisiones. Para dar paso posteriormente a una propuesta de un manual de procedimientos de aplicación de la evaluación de desempeño docente, cuyo contenido se alimente de la teoría jurídica, concretamente del Código de Procedimientos Civiles, mediante lo cual se garantice a cada docente evaluado los principios de legalidad y seguridad jurídica de los que todo ciudadano es poseedor.

\section{Referencias}

Aguilar, V. L. (2000). Estudio introductorio. En Aguilar, V. L. (ed.), El estudio de las políticas públicas (pp. 15-74). México: Porrúa.

Almandoz, M. R. (2005). Las lógicas de las decisiones políticas en educación. En Frigerio, G. y Diker, G. (comp.as), Educar: Ese acto político. Buenos Aires, Argentina: Del estante editorial.

Bourdieu, P. (2009). El oficio de sociólogo. México: Siglo XXI.

Carbonell, M. (2004). Los derechos fundamentales en México. México: UNAM.

Coll, C. (1996). Evaluación de los aprendizajes y atención a la diversidad. Signos. Teoría y práctica de la educación, (18), 64-67.

De la Garza, E. (1988). Hacia una metodología de la reconstrucción. Fundamentos, críticas y alternativas a la metodología y las técnicas de investigación social. México: PorrúaUNAM.

Delors, J. (1996). La educación encierra un tesoro. Madrid, España: Unesco.

Díaz, F. (2001). Constructivismo y evaluación psicoeducativa. En Díaz, F. y Hernández, G., Estrategias de enseñanza para la promoción de aprendizajes significativos. México: McGraw-Hill. 


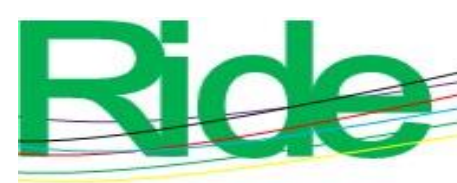

Revista Iberoamericana para la

Investigación y el Desarrollo Educativo

ISSN 2007 - 7467

Edelstein, G. y Rodríguez, A. (1974). El método factor definitorio y unificador de la instrumentación didáctica. Revista de Ciencias de la educación, 4(12), 21-33.

Faure, E. (1973). Aprender a ser. La educación del futuro. Milán, Italia: Alianza-Unesco.

Gouldner, A. (1980). La formación de los intelectuales y el ascenso de la nueva clase. España: Alianza.

Grawitz, M. (1975). Métodos y técnicas de las ciencias sociales. Barcelona, España: Hispano Europea.

Guba, E. and Lincoln, Y. (1989). Fourth generation evaluation. Newbury Park, United States: Sage.

Heller, H. (1992). Teoría del Estado. Buenos Aires, Argentina: Fondo de Cultura Económica.

Hume, D. (1980). Investigación sobre el conocimiento humana (J. Salas, trad.). Madrid, España: Alianza Editorial.

Instituto Nacional para la Evaluación de la Educación [INEE]. (2016). La evaluación del desempeño desde la experiencia de los docentes. Consulta con docentes que participaron en la primera evaluación de desempeño de 2015. México: Instituto Nacional para la Evaluación de la Educación.

Instituto Nacional para la Evaluación de la Educación [INEE]. (2017). Evaluación del desempeño de docentes, directivos y supervisores en educación básica y media superior en México. Análisis y evaluación de su implementación. Informe final. México: Orealc/Unesco.

Limoeiro, M. (1977). La construcción de conocimientos. cuestiones de teoría y método. México: Era.

Organización de las Naciones Unidas para la Educación, la Ciencia y la Cultura [Unesco]. (1990). Declaración mundial sobre educación para todos y marco de acción para satisfacer las necesidades básicas de aprendizaje. Conferencia mundial sobre educación para todos. Jomtien, Tailandia: Organización de las Naciones Unidas para la Educación, la Ciencia y la Cultura.

Paéz, A. (2014). La prueba testimonial y la epistemología del testimonio. Isonomía, (40).

Perujo, F. (2011). El investigador en su laberinto. La tesis, un desafío posible. Zamora, España: Comunicación social.

Popham, W. (1980). Problemas y técnicas de la evaluación educativa. Madrid, España: Anaya. 


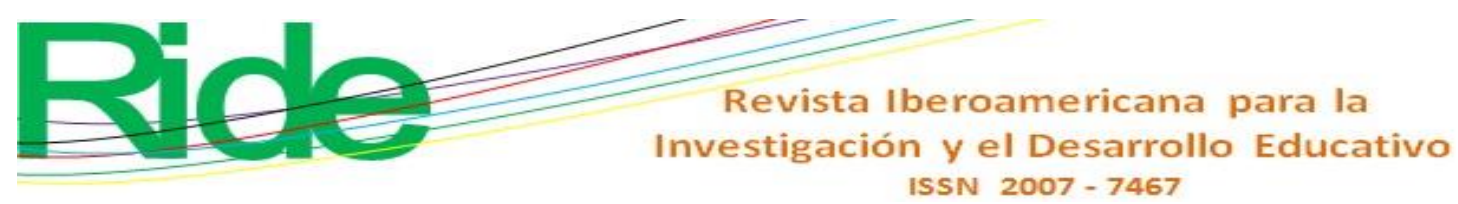

Reid, T. (1764). Inquiry into the Human Mind on the Principles of Common Sense. Edinburgh, Scotland: Edinburgh University Press.

Rosario, P. (2010). La filosofía de Karl Popper. Recuperado de http://pmrb.net/books/texts/karl_popper.pdf

Sacristán, G. (1998). La evaluación en la enseñanza. En Sacristán, G., Comprender y transformar la enseñanza (pp. 334-394). Madrid, España: Ediciones Morata.

Sánchez, R. (2000). Enseñar a investigar. Una didáctica nueva en la investigación de las ciencias sociales y humanas. En Sánchez, R., La trama y la urdimbre. México: UNAM-Plaza y Valdéz.

Shepard, L. (2006). La evaluación en el aula. En Brennan, R. (ed.), Educational Measurement (4.a ed.). Colorado, Estados Unidos: Universidad de Colorado, ACE/ Praeger Westport.

Torruco, S. (2009). El principio de legalidad en el ordenamiento jurídico mexicano. En Ríos, R., Reforma hacendaria en la agenda de la reforma del Estado (pp. 5-24). México: UNAMIIJ.

Toscano, J. (2002). Limites constitucionales al contenido material de las leyes de presupuestos del Estado. (tesis doctoral). Facultad de Derecho de la Universidad Pompeu Fabra, Barcelona.

Villa, F. (2013). ¿Qué significa investigar? Exorcismo del trabajo de investigación. México: FCE-BUAP.

Vita, L. (2015). La noción de principios jurídicos en la teoría del Derecho de Hermann Heller. Isonomia. Revista de teoría y filosofía del Derecho, (43), 49-75. 